\title{
Gestão compartilhada no Parque Nacional da Serra do Divisor [Acre]: desafios e oportunidades
}

\section{Ayri Saraiva Rando}

Doutorando em Engenharia Civil (Unicamp), Mestre em Desenvolvimento Regional pela Universidade Federal do Acre, Engenheiro Ambiental. Piracicaba [SP] Brasil <ayrirando@gmail.com>.

\section{Alisson Sobrinho Maranho}

Mestre em Ecologia e Manejo dos Recursos Naturais pela Universidade Federal do Acre, Engenheiro Florestal. Coordenador de Projeto na Associação SOS Amazônia. Rio Branco [AC] Brasil <alisson@sosamazonia.org.br>.

\section{Miguel Scarcello}

Mestre em Ciência Ambiental pela Universidade Federal Fluminense, Licenciado em Geografia. Secretário Geral da Associação SOS Amazônia. Rio Branco [AC] Brasil <miguel@sosamazonia.org.br>.

\section{Resumo}

A gestão de unidades de conservação é de extrema relevância ao desenvolvimento regional da Amazônia, somando-se os desafios da economia extrativa, das grandes obras de infraestrutura e os possíveis efeitos das mudanças climáticas. 0 baixo nível de implementação das unidades de conservação no Brasil, aliado à baixa ou média efetividade da gestão nas mesmas indicam a necessidade de mudanças na forma de gerir tais áreas protegidas. Este artigo analisa a gestão compartilhada como alternativa à elevação desta efetividade no Parque Nacional da Serra do Divisor, Acre. 0 mesmo utiliza-se da pesquisa bibliográfica e do levantamento documental.

\section{Palavras-chave}

Unidade de conservação. Recursos investidos. Gestão compartilhada.

\section{Shared management in the National Park of Serra do Divisor [state of Acre, Brazil]: challenges and opportunities}

\begin{abstract}
The management of protected areas is extremely important to regional development in the Amazon, adding to the challenges of the extractive economy, major infrastructure projects and the possible effects of climate change. The low level of implementation of the conservation units in Brazil, combined with low or average effectiveness of management in them indicate the need for changes in how to manage these protected areas. This article analyzes the shared management as an alternative to increase this effectiveness in Serra do Divisor National Park, Acre. The same uses bibliographical research and documental.
\end{abstract}

\section{Keywords}

Conservation unit. Invested resources. Shared management. 


\section{Introdução}

O desenvolvimento do Acre, a implementação do Sistema Nacional de Unidades de Conservação e a gestão das Unidades de Conservação (UCs) neste estado apresentam diversos desafios, pois envolvem aspectos como a economia extrativa, a implantação da infraestrutura de energia e de transporte, incluindo ainda a gestão das unidades citadas e os possíveis efeitos das mudanças climáticas.

Além disso, tal estado encontra-se em região de fronteira entre unidades subnacionais marcadas pela floresta tropical na Amazônia Sul Ocidental, fazendo divisa com os estados do Amazonas e de Rondônia, no Brasil. Na Bolívia, com o departamento de Pando e, no Peru, com os departamentos de Madre de Dios, Ucayali e Loreto.

A Infraestrutura regional e atual inclui os asfaltamentos recentes da BR-317, que liga o município de Boca do Acre no Amazonas a Puerto Maldonado no Peru, passando pelo Vale do Rio Acre, pela capital do Acre - Rio Branco e pela capital do departamento de Pando - Cobija; o asfaltamento ainda mais recente da BR-364, no trecho de Rio Branco a Cruzeiro do Sul, que é a segunda maior cidade do Acre em população, integrando boa parte do estado mencionado. A infraestrutura em questão vincula também a construção de linha de transmissão de energia elétrica de Sena Madureira a Cruzeiro do Sul às margens da BR-364 e o bloco AC T-8 arrematado para exploração de gás e petróleo pela PETROBRAS na região do Vale do Juruá, próximo a Cruzeiro do Sul.

Ao permanecer na análise da infraestrutura, enfatiza-se que há proposta de construção de estrada ligando a capital do departamento de Ucayali, Pucallpa, a Cruzeiro do Sul. Caso esta proposta seja executada, o Parque Nacional da Serra do Divisor (PNSD) estará situado na área de influência desta estrada.

Em um estado onde cerca de 45\% do seu território é formado por Áreas Protegidas (Unidades de Conservação e Terras Indígenas), a implementação dos sistemas nacional e estadual de unidades de conservação, e a gestão de tais áreas, se tornam temas extremamente relevantes ao desenvolvimento regional.

A criação, implementação e boa gestão de UCs são estratégias globalmente reconhecidas para garantia do modo tradicional de vida de diversas populações e dos respectivos direitos, e para preservação e conservação da biodiversidade. No Brasil e no Acre em geral, o nível de gestão destas unidades não é alto, demanda investimentos mais significativos referentes aos recursos financeiros e humanos, e necessita novas formas de gestão que gerem receita, supram a carência de recursos humanos, possibilitem, agilizem e fortaleçam as propostas de projetos de captação de recursos.

Este artigo aborda o tipo de gestão adotado no PNSD no Acre e uma breve análise sobre a efetividade de tal gestão na unidade de conservação mencionada.

O objetivo geral do mesmo é avaliar a efetividade da gestão em pauta. Já, o objetivo específico é analisar a gestão compartilhada como alternativa à elevação de tal efetividade no parque em questão.

Tal artigo utiliza-se da pesquisa bibliográfica e do levantamento documental. Sua área de estudo é o parque nacional mencionado (Figura 3).

\section{A importância das unidades de conservação}

A estratégia de manter áreas sobre regime especial de proteção já existe no mundo a mais de 500 anos, no entanto, com os nomes de parques, reservas ou áreas protegidas, sendo o primeiro deles o Parque Nacional de Yellowstone, em Wyoming (Estados Unidos da América), criado em 1872 (WWF Brasil \& IPÊ, 2012).

Segundo WWF Brasil e IPÊ (2012), o primeiro parque nacional brasileiro foi o de Itatiaia, estabelecido em 1937, seguido da criação do Parque Nacional da Serra dos Órgãos e do Parque Nacional de Iguaçu, em 1939. 
Oliveira (2013) comentou que as UCs são áreas que fazem parte da estratégia mundial de conservação da biodiversidade, ratificada pela Convenção das Nações Unidas sobre Diversidade Biológica (CDB), cujo objetivo é a redução significativa na perda da biodiversidade em nível global. Comentou também que no Brasil as UCs federais, estaduais e municipais ocupam aproximadamente $17 \%$ do território nacional e as áreas destas unidades na Amazônia totalizam 1,1 milhão de $\mathrm{km}^{2}$, o que equivale à área maior que a soma dos territórios da França e da Espanha. Em relação às UCs federais, existem 313 no Brasil, sendo 107 delas no bioma Amazônia, correspondendo a 80\% da área total de tais unidades federais. Na Amazônia brasileira, há 247 unidades federais e estaduais, sendo 107 federais e 140 estaduais.

Conforme Medeiros et al. (2011), as UCs são mundialmente reconhecidas como instrumentos fundamentais à conservação de espécies, populações e ecossistemas, considerando os sistemas e meios tradicionais de sobrevivência de comunidades humanas. Além disso, o Brasil é um dos países signatários da CDB, assumindo assim, a missão de criar e manter adequadamente uma rede de tais unidades, com a finalidade de conservar a diversidade biológica, de utilizar racionalmente seus componentes e repartir justamente e equitativamente os benefícios oriundos do uso dos recursos genéticos.

Na década equivalente ao período de 2001 a 2010, após a criação do Sistema Nacional de Unidades de Conservação (SNUC), em 2000, o país promoveu uma significativa expansão da superfície coberta pelas unidades mencionadas, primordialmente na Amazônia, sendo que o país citado foi responsável por 74\% de todas as áreas protegidas criadas em todo o mundo, entre 2003 e 2008. Juntas, as UCs das diferentes categorias do SNUC recobrem aproximadamente 15\% do território nacional (Medeiros et al., 2011).

Tratando-se da estimativa do potencial econômico decorrente da exploração de produtos florestais madeireiros (madeira em tora) e não madeireiros (borracha e castanha-do-pará) para as UCs do bioma Amazônia (Florestas e Reservas Extrativistas), Medeiros et al. (2011) frisaram que pode variar de $\mathrm{R} \$ 1,3$ bilhão, em um cenário mais conservador, a $\mathrm{R} \$ 2,3$ bilhões anuais, em um cenário mais otimista.

Ainda segundo Medeiros et al. (2011), as estimativas do impacto do turismo em Parques Nacionais sobre as economias locais foram calculadas sobre o cenário atual, que estima o impacto econômico da visitação com base no fluxo atual de visitantes; e o cenário potencial, o qual estima o impacto econômico da visitação considerando uma projeção do número de visitantes aos parques, a partir da consolidação da estrutura mínima necessária nestas áreas, enfatizando-se que, dos 67 Parques Nacionais presentes no Cadastro Nacional de Unidades de Conservação, apenas 18 possuem visitação estruturada, com controle do fluxo de visitantes e cobrança de ingressos. Apresenta-se a estimativa do potencial do impacto econômico da visitação nos 67 Parques Nacionais, em 2016 (Tabela 1).

Tabela 1. Estimativa do potencial do impacto econômico da visitação nos 67 Parques Nacionais, em 2016.

\begin{tabular}{cccc}
$\begin{array}{c}\text { Número de Unidades } \\
\text { incluídas na Categoria }\end{array}$ & $\begin{array}{c}\text { Número de Visitantes } \\
\mathbf{( 2 0 1 6 )}\end{array}$ & $\begin{array}{c}\text { Impacto Econômico no } \\
\text { Cenário Conservador } \\
\text { (Bilhões R\$/ano) }\end{array}$ & $\begin{array}{c}\text { Impacto Econômico no } \\
\text { Cenário Otimista } \\
\text { (Bilhões R\$/ano) }\end{array}$ \\
\hline 67 & 13.759 .367 & 1,6 & 1,8 \\
\hline
\end{tabular}

Fonte: Medeiros et al., 2011.

É de extrema importância destacar que a concretização de tal potencial de impacto econômico em 2016 depende diretamente do recebimento de investimentos necessários à consolidação das unidades em questão para que estejam aptas a receber o número de visitantes estimado.

Outro aspecto relevante, de acordo com Medeiros et al. (2011), é o potencial econômico das reservas de carbono em UCs, sendo que o conjunto destas unidades brasileiras teria impedido a emissão na atmosfera de cerca de 2,8 bilhões de toneladas de carbono, cerca de 1,3 vezes as emissões brasileiras totais de 2005, o que significa, em termos conservadores, o estoque total de emissões evitadas de carbono é igual a quase $\mathrm{R} \$ 100$ bilhões. 
Portanto, a implementação de instrumentos econômicos para conservação florestal pode propiciar a oportunidade de novas fontes de financiamento para a criação de novas UCs e principalmente para a consolidação das já existentes, possibilitando ainda o cumprimento de metas climáticas assumidas pelo Brasil, a redução da pobreza e a conservação da biodiversidade.

Segundo Araújo et al. (2016), em 2013, os Tribunais de Contas da União (TCU) e dos Estados (TCEs) constataram que apenas $4 \%$ de tais UCs possuíam alto grau de implementação, o que significa dizer que estavam recebendo os recursos, instrumentos e infraestrutura necessários à sua gestão e alcançando plenamente seus objetivos. Os mesmos comentaram que a falta ou insuficiência de implementação torna as unidades em pauta vulneráveis à exploração ilegal de produtos e à ocupação de grileiros, sendo que 46 (92\%) das 50 UCs mais desmatadas da Amazônia entre 2012 e 2014 apresentavam baixa ou média implementação (ARAÚJ0 et al., 2016).

Ainda de acordo com Araújo et al. (2016), entre 2008 e 2015, 467 mil hectares foram desmatados nas UCs da região, destruindo aproximadamente 233 milhões de árvores e causando a morte ou o deslocamento de aproximadamente 8,3 milhões de aves e 271 mil macacos. Estimaram-se que a queima da vegetação em tal área desmatada tenha resultado na emissão de 29 milhões de toneladas de dióxido de carbono equivalente por ano entre 2008 e 2015, comparável à emissão deste gás por 10 milhões de automóveis por ano.

Outro aspecto que mostra a relevância da implantação das áreas protegidas em questão é que, recentemente, órgãos de fiscalização como o TCU e o Ministério Público Federal (MPF) demandaram a implementação das UCs no país e, principalmente, na Amazônia (Araújo et al., 2015).

No Acre, as áreas protegidas são ainda mais relevantes devido ao seu contexto histórico, à porção do território delimitada por tais áreas e às populações tradicionais que dependem dos recursos disponíveis nas mesmas.

Em relação ao contexto histórico, é importante executar um breve resgate, ressaltando que a economia da borracha iniciou um processo econômico na região amazônica no final do século XIX, fixando a população migrante nos seringais. Tal economia teve dois períodos de grande relevância e geração de riqueza: um que se refere ao final do século citado e princípios do século XX, e o segundo no período da Segunda Guerra Mundial (IBGE, 2009).

Ainda de acordo com IBGE (2009), esta economia não estabeleceu uma produção regular no cenário econômico regional e nacional, além de não distribuir benefícios à população ocupada, concentrando os benefícios gerados em poucas mãos. A queda da produção e novos processos econômicos que atingiram a região superou os interesses da extração da borracha e da castanha, passando à exploração madeireira e à pecuária, constituindo novos processos de avanço da fronteira econômica, capitaneados pela agropecuária. Os processos mencionados começaram na década de 1970 com as mudanças na estrutura agrária e na economia do estado, trazendo novas formas de conflitos.

Os grupos sociais e econômicos tradicionais denominados "Seringueiros" estiveram frente a grupos novos, que eram os fazendeiros representantes dos processos pioneiros de produção agropecuária. A luta entre estes grupos foi pelas contradições existentes entre os mesmos e fortaleceu o movimento social dos seringueiros, que influenciou diretamente na criação de uma das primeiras Reservas Extrativistas (RESEX) do Brasil, que foi a RESEX Chico Mendes no Acre, que é um dos tipos de unidades de conservação do país, classificada como UC de uso sustentável (IBGE, 2009).

0 estado mencionado tem 17 UCs e 35 Terras Indígenas (TIs), estas áreas representan aproximadamente $45 \%$ do territorio acreano (Tabela 2) e contam com uma população de 18.240 indígenas. Como a população total do Acre, em 2013, era de 776.463 habitantes, os indígenas representavam cerca de $2,3 \%$ da população citada.

Segundo a Secretaria de Estado de Planejamento do Acre (2013), há 3 unidades de conservação de proteção integral e 17 unidades de conservação de uso sustentável. 
Tabela 2. Áreas naturais protegidas do Acre.

\begin{tabular}{|ccc|}
\hline Categoria & Área (Mha) & Percentagem do Estado (\%) \\
\hline Unidades de Conservação de Proteção Integral & 1,6 & 9,5 \\
\hline Unidades de Conservação de Uso Sustentável & 3,6 & 21,7 \\
\hline Terras Indígenas & 2,4 & 14,6 \\
\hline Áreas Naturais Protegidas & 7,5 & 45,8 \\
\hline Área Total do Estado & $\mathbf{1 6 , 4}$ & $\mathbf{1 0 0 , 0}$ \\
\hline
\end{tabular}

Fonte: Acre, 2013.

\section{Gestão de unidades de conservação no Brasil}

Para Brasil (2000), as unidades de conservação são espaços territoriais e seus recursos ambientais, incluídas as águas jurisdicionais, com características naturais relevantes, legalmente instituído pelo poder público, com os objetivos de conservação e limites definidos, as quais se aplicam, sob regime especial de administração, garantias adequadas de proteção.

Brasil (2000) definiu duas categorias de UCs, uma de proteção integral e outra de uso sustentável. As UCs de proteção integral são aquelas utilizadas para a manutenção dos ecossistemas livres de impactos causados pela interferência humana, admitindo só o uso indireto dos seus atributos naturais, sendo tal uso o que não implica em consumo, extração, dano ou em destruição dos recursos naturais.

As UCs de uso sustentável são aquelas que permitem a exploração do meio ambiente com a finalidade de garantir a sustentabilidade dos recursos ambientais renováveis e dos processos ecológicos, mantendo a biodiversidade e outros atributos ecológicos, de forma socialmente justa e economicamente viável. Esta categoria pretende conciliar a conservação da natureza com o uso sustentável de parte dos seus recursos naturais (Brasil, 2000).

O controle e a participação social passaram a incorporar o desenho e a implantação das políticas públicas no Brasil a partir da Constituição de 1988. Já, esta abordagem referente à gestão participativa no âmbito das UCs é realizada através de conselhos gestores (Brasil, 2000; Acre, 2001). Para Loureiro et al. (2008), tais conselhos são definidos como espaço público jurídico-institucional, que tem por excelência a intervenção social atrelada e planejada na formulação e implementação de políticas públicas.

Em UCs de proteção integral, os conselhos são consultivos, dados os limites previstos em lei. No caso das UCs de uso sustentável, prevê que o conselho seja deliberativo para as categorias Reserva Extrativista (RESEX) e Reserva de Desenvolvimento Sustentável (RDS).

A população deve ser envolvida nos processos de construção das políticas públicas, da criação das normas e da fiscalização ambiental destas unidades, no qual os usuários de tais recursos, as autoridades competentes, os pesquisadores e qualquer ator interessado somem esforços para o cumprimento dos objetivos pertinentes à criação das unidades mencionadas. Para Malheiros et al. (s.d.), este envolvimento da população nas ações citadas voltadas ao gerenciamento das áreas protegidas caracteriza uma nova maneira de lidar com a natureza, conhecida como Gestão Participativa ou Gestão Compartilhada das mesmas.

Voltando aos conselhos gestores, segundo Malheiros et al. (s.d.), eles são entidades criadas para aplicar a gestão participativa da UC, reunindo os gestores ou técnicos do Instituto Chico Mendes de Conservação da Biodiversidade (ICMBio), os representantes das comunidades, dos órgãos governamentais, das instituições de fiscalização, das organizações não governamentais (ONGs) e dos demais interessados, com o intuito de discutir problemas e estratégias regionais para a conservação ambiental e melhoria da qualidade de vida da população que reside na área ou no seu entorno. 
De acordo com o Decreto $\mathrm{n}^{\circ} 4.340$, de 22 de agosto de 2002, a gestão compartilhada da unidade de conservação se dá por Organização da Sociedade Civil de Interesse Público (OSCIP) e é regulada por termo de parceria firmado com o órgão executor, que é o ICMBio. Entre as ações que podem ser realizadas pelos conselhos, enfatizam-se o acompanhamento da elaboração, implementação e revisão do plano de manejo, garantindo o seu caráter participativo; a avaliação do orçamento da unidade e do relatório financeiro anual produzido pelo órgão executor; a opinião, no caso de conselho consultivo, ou a ratificação, no caso de conselho deliberativo, sobre a contratação e os dispositivos do termo de parceria com OSCIP, na hipótese de gestão compartilhada; o acompanhamento da gestão por OSCIP e a recomendação de rescisão do termo de parceria, quando constatada irregularidade (Brasil, 2002).

A implantação e a gestão das UCs não seguiram o ritmo de ampliação alcançado pelo SNUC entre 2001 e 2010, portanto, viabilizar a consolidação de tais áreas é o primeiro desafio identificado. A efetividade da gestão é outro grande desafio, pois enfrenta problemas, como regularização fundiária das terras declaradas como UCs, falta de funcionários e de infraestrutura básica, ausência de plano de manejo ou planos de manejo não revisados. 0 investimento insuficiente é apontado como a principal causa destes problemas (Medeiros et al., 2011).

Segundo MMA (2011 apud Medeiros et al., 2011), o orçamento para as UCs federais é praticamente o mesmo desde 2001, ou seja, cerca de $\mathrm{R} \$ 300$ milhões por ano. Porém, no mesmo período, a área total das UCs em questão expandiu 83,5\%, isto significa que os recursos alocados por hectare federal protegido sofreram uma redução aproximada de 40\% entre 2001 e 2010.

A título de comparação para demonstrar o baixo investimento brasileiro, o orçamento destinado às áreas protegidas no Brasil correspondia em 2010 a $\mathrm{R} \$ 4,43$ por hectare destas áreas, enquanto que na Argentina este valor equivalia a $\mathrm{R} \$ 21,37$, na África do Sul R $\$ 67,09$ e nos Estados Unidos $\mathrm{R} \$ 156,12$ (Figura 1), notando-se que mesmo países com Produto Interno Bruto menores que o brasileiro investem, por hectare protegido, 4,8 vezes mais no caso da Argentina e 15,1 vezes mais no caso da África do Sul para manutenção dos seus sistemas.

Figura 1. Investimento por hectare de unidade de conservação em diferentes países.

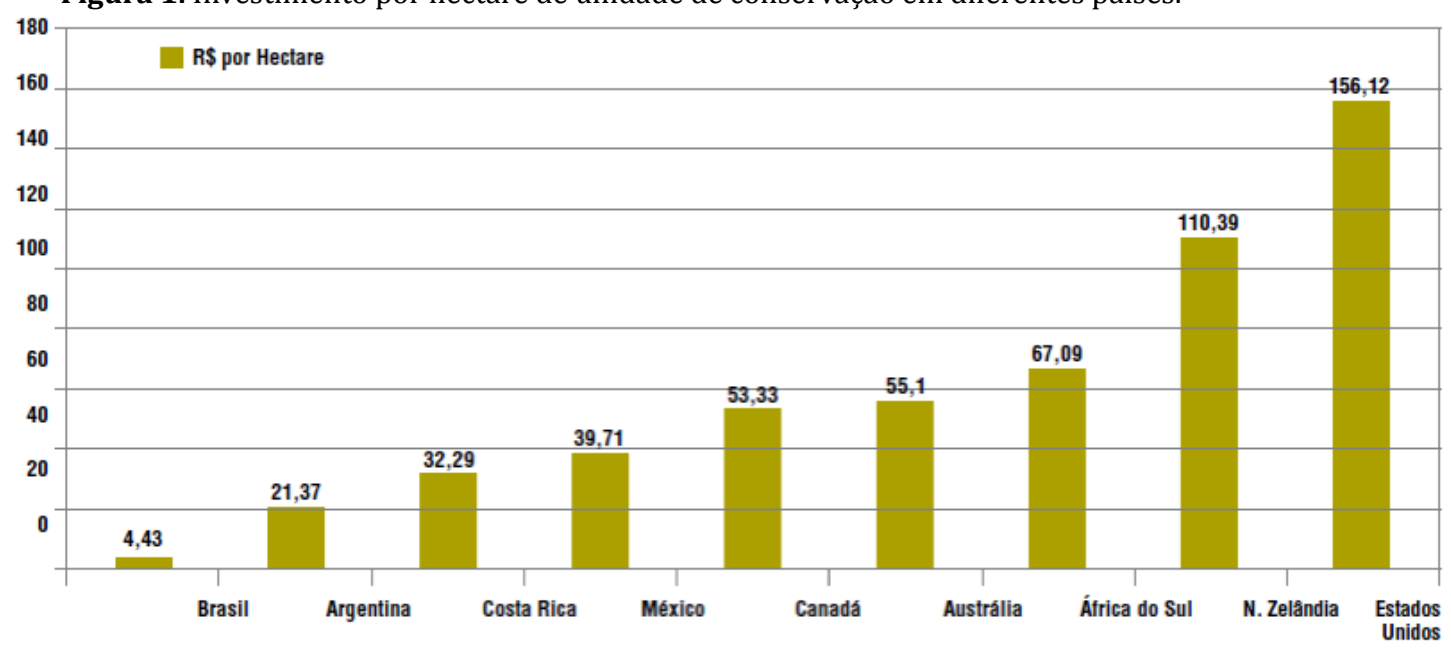

Fonte: CNUC, 2010 apud Medeiros et al., 2011.

Medeiros et al. (2011), ao comparar o número de funcionários alocados na gestão de tais unidades, indicaram que o Brasil também não está em situação confortável perante outros países, ficando entre os piores do mundo. Por exemplo, a relação é de um funcionário para cada 2400 hectares na Argentina, é de um funcionário para 1176 hectares na África do Sul, é de um funcionário para 2125 hectares nos Estados Unidos e é de um funcionário para 18600 hectares no Brasil.

A abordagem pertinente à efetividade da gestão de UCs continua com Oliveira (2013), o qual frisou a utilização do Indimapa como nova forma de avaliar a implementação e a gestão das UCs através de índice, observando que a auditoria coordenada do TCU em UCs no bioma Amazônia 
chegou as seguintes conclusões: as unidades em pauta não atingem plenamente os resultados esperados; as condições disponibilizadas pelo Governo Federal não são compatíveis com as necessidades de tais unidades; articulação insuficiente para o alcance dos objetivos das unidades de conservação; baixa utilização do potencial de uso público para visitação, turismo e recreação; número pequeno de concessões florestais onerosas em exploração; dificuldades na promoção de atividades extrativistas; inexistência, inadequação e baixo grau de implementação dos planos de manejo; consolidação territorial incipiente; coordenação do SNUC insuficiente; baixa cooperação entre os atores que possuem interface com este sistema nacional; e frágil comunicação entre os mesmos.

A gestão compartilhada de UCs aparece como parte da solução para superar os desafios e aumentar a sua efetividade. No sentido de melhorar a gestão e a implementação das UCs, Araújo et al. (2016) recomendaram a ênfase em ações preventivas nas regiões em torno das grandes obras de infraestrutura. A promoção do uso sustentável destas unidades é outra recomendação para aumentar o interesse local na integridade das mesmas, o que inclui atividades de turismo, pesquisa científica e manejo florestal.

A visitação aos parques nacionais do país pode gerar anualmente até $\mathrm{R} \$ 1,8$ bilhão para as regiões onde estão localizados, sendo que algumas UCs na Amazônia já recebem visitantes, mas falta estrutura para recebê-los e para gerar receitas, como controle de entrada e cobrança de ingresso. Para acelerar o uso das UCs é possível adotar as Parcerias Público-Privadas (PPP), que garantem agilidade à prestação de serviços e requerem baixo investimento do poder público (Araújo et al., 2016).

Na sequência, destacam-se as propostas dos Tribunais de Contas aos órgãos ambientais do bioma Amazônia para melhoria da gestão e da implementação de UCs (Figura 2).

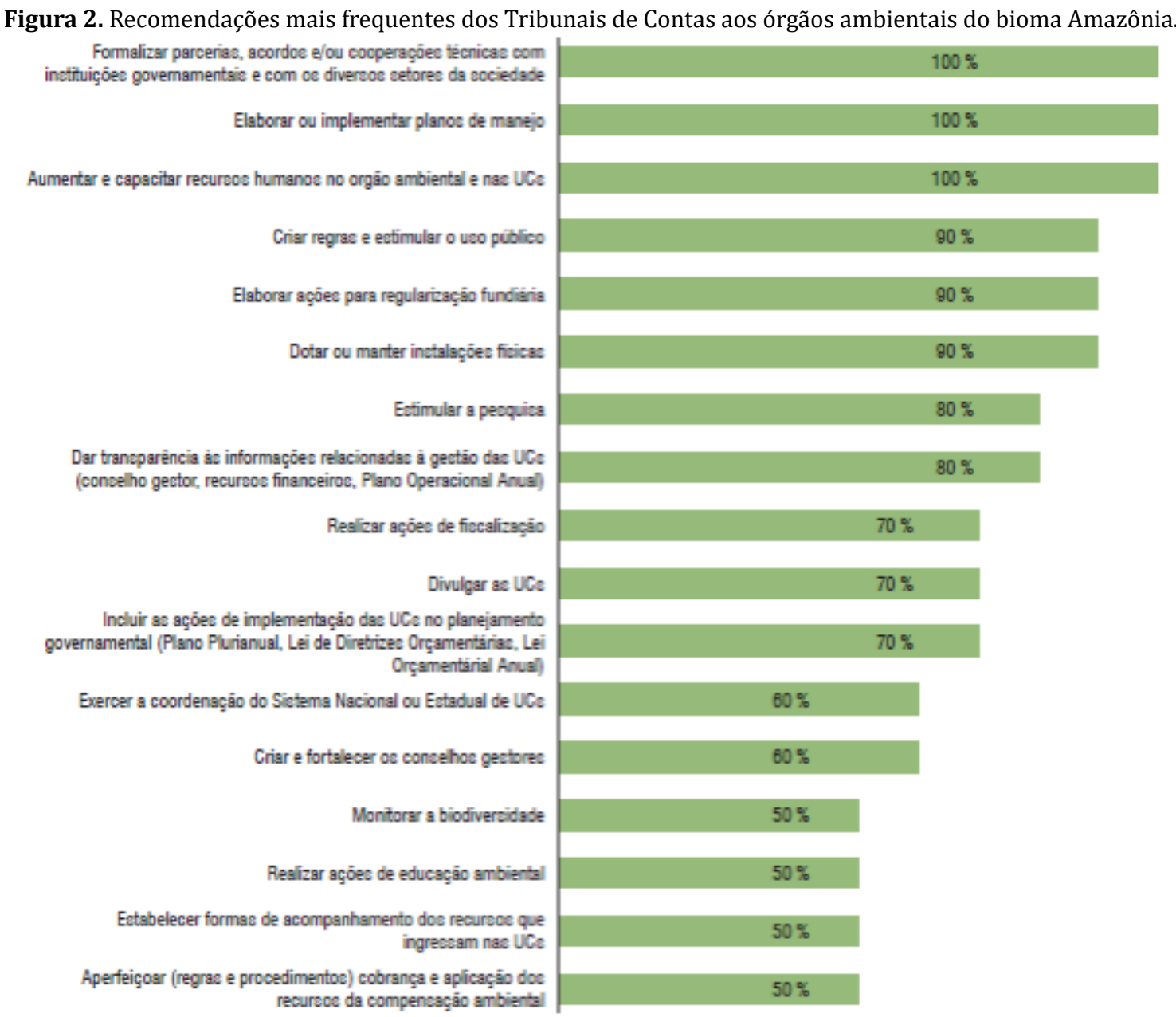

Fonte: Araújo, et al., 2016. 
Em relação aos recursos humanos, os Tribunais de Contas recomendaram cooperação entre órgãos governamentais e parceria com instituições de pesquisa, sociedade civil organizada e setor privado para suprir a carência de pessoal, frisando que o Acre instituiu uma meta de estabelecimento de parceria dentro de um ano (Araújo et al., 2016).

Tratando-se de recursos financeiros, a maioria das UCs não possui atividades de geração de renda para a sua gestão, tais como a visitação e a concessão florestal, justamente devido à ausência ou baixa implementação de planos de manejo (TCU, 2013 apud ARAÚJO et al.,2016). Acrescentase ainda que nem todas as UCs recebem recursos do programa Áreas Protegidas da Amazônia (ARPA) (105 UCs ou 40\%) ou de compensação ambiental, o que indica a necessidade de destinação de recursos orçamentários ou propostas de projetos pertinentes à captação de recursos (Araújo et al., 2016).

Araújo et al. (2015 apud Araújo et al., 2016), mencionaram que o TCU estimou que, seriam necessários cem anos para concluir a regularização fundiária das UCs, no caso de continuar com os mesmos investimentos recentes, entretanto, outros estudos apontaram que há várias fontes de recursos para custear a gestão em questão, por exemplo, coleta de multas ambientais e venda de parte das terras públicas já ocupadas irregularmente fora destas unidades.

Para Araújo et al. (2015), o êxito de tais áreas protegidas contra o desmatamento e a favor do desenvolvimento local depende de investimentos. Com o intuito de garantir a integridade destas áreas, recomendaram punição de todos os crimes associados ao desmatamento ilegal, fiscalização ambiental exemplar, retirada de ocupantes não tradicionais das UCs em que sua permanência não é permitida e retomada de terras públicas fora das unidades citadas.

\subsection{Experiências de gestão compartilhada de unidades de conservação no Amazonas}

A gestão compartilhada de UCs acontece quando o governo cede ou socializa tal gestão com uma OSCIP por meio da celebração de convênios, contratos de repasse, termos de cooperação ou termos de parceria.

O mecanismo de cogestão utilizado pelo IBAMA no Parque Nacional da Serra da Capivara no Piauí, no Parque Nacional Grande Sertão Veredas em Minas Gerais, no Parque Nacional da Serra do Divisor no Acre e no Parque Nacional Jaú no Amazonas, ajudou a melhorar a gestão destas áreas protegidas, o que o caracteriza como mecanismo passível de ser replicado em certas circunstâncias (Koury \& Guimarães, 2012).

Segundo Pádua (2000), tal tipo de gestão pode ser e tem sido um excelente mecanismo de fazer a captação de recursos financeiros e para dar mais flexibilidade na contratação de pessoal, sem contar que as ONGs possuem maior credibilidade e são mais facilmente aceitas no campo, junto às comunidades, do que a instituição pública gestora.

Uma possível definição para cogestão é que a mesma "significa desenvolvimento de atividades em parceria para alcançar um objetivo comum, sem que isso signifique alterar as competências de cada órgão envolvido, ou diminuir seu poder e/ou suas responsabilidades" (Ramos, 1998 apud Koury \& Guimarães, 2012).

Enfim, o consenso é que independentemente do modelo de gestão, ele deve fomentar a participação social através de ações referentes à promoção dos conselhos gestores, inclusive com assinatura de termo de cooperação técnica entre o órgão público gestor e as ONGs para implantação das ações previstas nos planos de manejo da UC. Gestão esta, chamada de gestão participativa.

Koury e Guimarães (2012) enfatizaram que o Amazonas tem experiências exitosas em parceiras com a sociedade civil a partir de Termos de Cooperação Técnica para apoiar a implementação das unidades. Já, na esfera federal, mencionaram que o estado em pauta possui parceria entre o ICMBio e a Fundação Vitória Amazônica (FVA), no Parque Nacional do Jaú, e com o Instituto de Pesquisas Ecológicas (IPÊ), no Parque Nacional de Anavilhanas (IDESAM, 2009). O Termo de Cooperação Técnico-Científica também foi outro instrumento adotado pelo Governo do Estado 
do Amazonas para a parceria com ONGs na gestão e implementação de UCs (Koury \& Guimarães, 2012).

Koury e Guimarães (2012) afirmaram ainda que as parcerias com a sociedade civil representavam uma atuação em 12 UCs estaduais, 3 federais e 1 UC municipal, abrangendo uma área de atuação de mais de 12 milhões de hectares no Amazonas, o que representava mais de $25 \%$ das UCs geridas pelo Governo do Amazonas e pouco mais de $6 \%$ das UCs federais dentro deste estado.

O ponto positivo identificado na gestão compartilhada de UCs em tal unidade da federação é o investimento anual de mais 1 milhão de reais das ONGs nas áreas protegidas que atuam, apoiando, portanto, a implantação do sistema nacional e do sistema estadual. Por outro lado, IDESAM (2009) reconheceu a carência de investimentos para garantir a conservação e os objetivos de criação das áreas protegidas em questão.

\subsection{Gestão de unidades de conservação no Acre}

O Sistema Estadual de Áreas Naturais Protegidas do Acre (SEANP) é política que segue o SNUC. A estrutura institucional estadual para a gestão dos recursos florestais envolve o Conselho Florestal Estadual (CFE) e o Conselho Estadual de Meio Ambiente, Ciência e Tecnologia (CEMACT), no que diz respeito ao controle social e à promoção da gestão participativa (Acre, 2001).

Como tal artigo aborda aspectos do Parque Nacional da Serra do Divisor, a participação e a descentralização da gestão inclui a criação e o funcionamento do Conselho Gestor desta UC.

Uma análise integrada das UCs Federais e Estaduais do Acre sobre efetividade da gestão destas unidades foi feita através do método de Avaliação Rápida e Priorização da Gestão de Unidades de Conservação (Rappam). Tratando-se dos insumos, enfatiza-se a elevada capacidade para captação de recursos e perspectiva média de fundos para o futuro, no entanto, há fatores críticos, como o número de pessoas, as condições de trabalho e os recursos financeiros existentes no passado, influenciando negativamente a gestão das unidades citadas (WWF Brasil et al., 2009).

Segundo WWF Brasil et al. (2009), das 17 UCs avaliadas, 10 apresentam efetividade de gestão média, 6 apresentam efetividade baixa e 1 expõe efetividade alta. Ao analisar os dois grupos de unidades de conservação, uso sustentável e proteção integral, frisa-se que ambos apresentam efetividade e vulnerabilidade médias e resultados baixos.

Enfim, como já mencionado, a área de estudo deste artigo é o PNSD (Figura 3), o qual possui superfície de 843.012,28 hectares e situa-se no extremo oeste do estado do Acre, na região do Alto Rio Juruá, fronteira com o Peru, na microrregião denominada Cruzeiro do Sul, abrangendo áreas de cinco municípios: Cruzeiro do Sul, Mâncio Lima, Rodrigues Alves, Porto Walter e Marechal Thaumaturgo. Ao traçar uma linha reta, fica aproximadamente a $700 \mathrm{Km}$ da capital do estado, Rio Branco, a $90 \mathrm{Km}$ da cidade de Cruzeiro do Sul e à $150 \mathrm{Km}$ da cidade de Pucallpa, Departamento de Ucayali, no Peru (Associação SOS Amazônia et al., 1998).

\subsubsection{Experiência da SOS Amazônia na gestão do Parque Nacional da Serra do Divisor}

O Decreto Federal No 97.839, de 16 de junho de 1989 cria o Parque Nacional da Serra do Divisor, no estado do Acre, com o objetivo de proteger e preservar amostra dos ecossistemas existentes nesta região, assegurar a preservação de seus recursos naturais, proporcionando oportunidades controladas para uso pelo público, educação e pesquisa científica.

De acordo com Brasil (2000), a categoria de UC denominada Parque Nacional visa a preservação de ecossistemas naturais de grande relevância ecológica e beleza cênica, além de possibilitar a realização de pesquisas científicas e o desenvolvimento de atividades de educação e interpretação ambiental, de recreação e de turismo ecológico. Observa-se também que a visitação pública está sujeita às regras e restrições estabelecidas no plano de manejo ${ }^{1}$ da unidade, às normas estabelecidas pelo órgão responsável por sua administração, e àquelas previstas em regulamento.

O bioma onde localiza-se esta UC é o amazônico com ecossistemas de Floresta Ombrófila Densa,

(C) Labor \& Engenho, Campinas [SP] Brasil, v.11, n.1, p.05-17, jan./mar. 2017. 
de Floresta Ombrófila Aberta e de Floresta Aluvial (Associação SOS Amazônia et al., 1998).

Figura 3. Localização do Parque Nacional da Serra do Divisor, Acre.

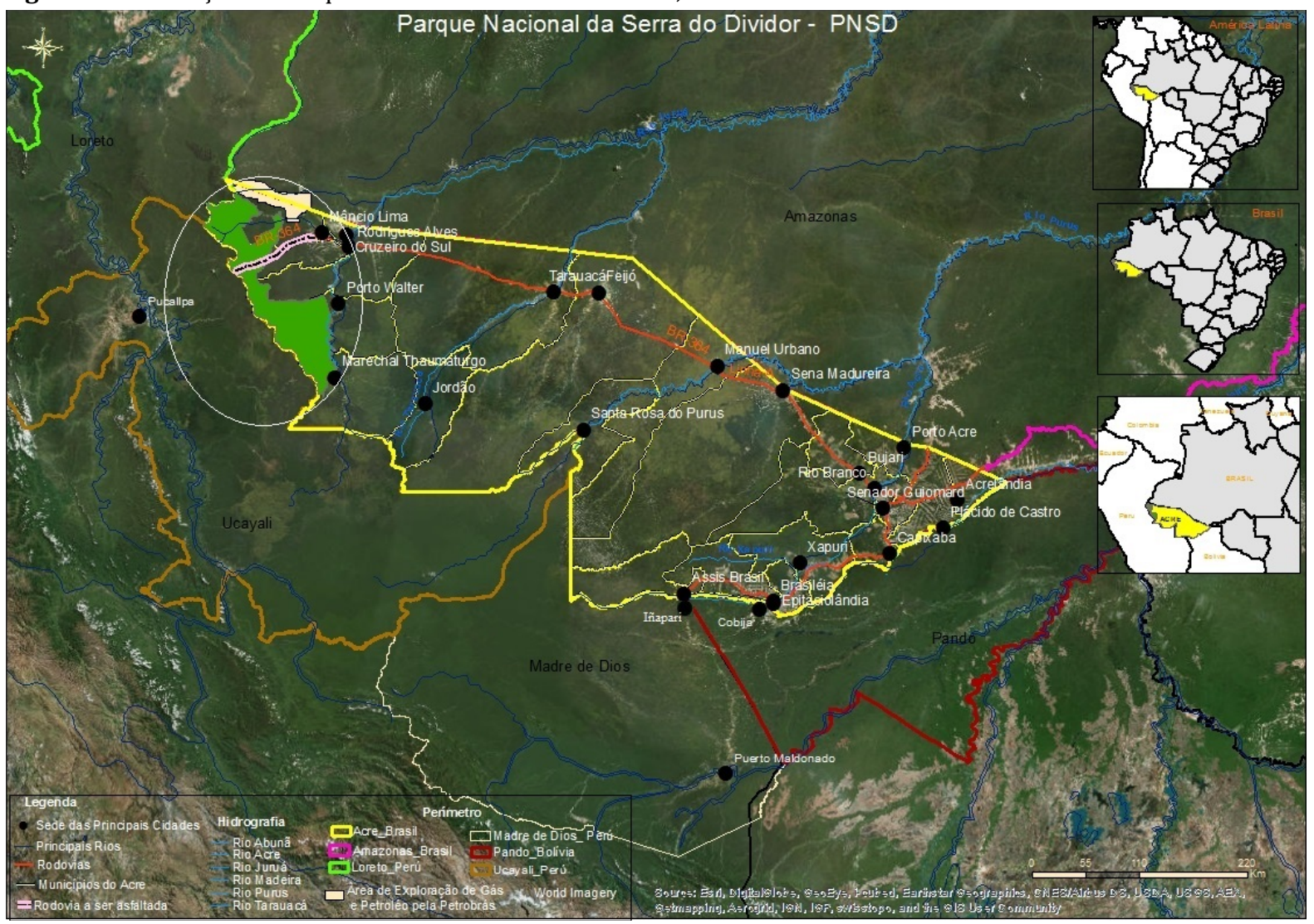

Fonte: ZEE/AC e INPE, s. d.

Em relação às atividades desenvolvidas em tal parque, a Associação SOS Amazônia et al. (1998) ressaltaram a fiscalização com visitas eventuais do órgão gestor e fiscalizador, o ICMBio, em resposta às denúncias de caça e extração de madeira. Já, tratando-se das atividades que geram conflitos, frisaram-se a ocupação humana, o extrativismo não madeireiro da seringa, palhas e cipós, o extrativismo madeireiro, a agricultura, a pecuária, o desmatamento, a criação de animais domésticos, a caça e pesca de subsistência e comercial, o comércio de peles, a extração de fósseis e pedras pomes, as mudanças artificiais nos cursos dos rios e os acampamentos.

Como atividades recreativas de uso público, destacaram-se as caminhadas, os banhos e os acampamentos, porém, as mesmas ainda não são regulamentadas (Associação SOS Amazônia et al., 1998).

Entre as ações desenvolvidas pela Associação SOS Amazônia no PNSD, destacam-se: em 1995, participação na elaboração do plano de manejo; em 2001, apoio à criação do conselho consultivo e realização de estudo e levantamento de dados para regularização fundiária com envolvimento do Instituto Brasileiro do Meio Ambiente e dos Recursos Naturais Renováveis (IBAMA), e do Instituto de Terras do Acre (ITERACRE) e 222 famílias; em 2001-2002, participação na elaboração do plano de uso público do parque, em conjunto com o Programa de Ecoturismo da Amazônia; em 2002, realização de 5 cursos de introdução ao ecoturismo para melhorar a utilização turística de tal parque, monitoramento ambiental do mesmo e participação na execução do Projeto Conectando Comunidades Florestais e Paisagens para o Desenvolvimento Sustentável do Sudoeste da Amazônia Brasileira (Consórcio Amazoniar); em 2004, conclusão do plano de uso público e participação na execução de novo projeto de conservação na fronteira da Serra do Divisor entre Brasil e Peru; em 2007, envolvimento direto no projeto de apoio à gestão socioambiental no entorno do PNSD; em 2007-2010, Projeto Quelônios do Juruá - Eu Protejo; em 2008-2009, atuação no entorno do parque com promoção do uso sustentável de recursos florestais não madeireiros em comunidades extrativistas do Vale do Juruá; em 2009-2012, envolvimento direto com o Projeto Fortalecendo a Integração Fronteiriça Acre-Ucayali; e em 2014-2017, execução do Projeto de Assistência Técnica e 
Extensão Rural (ATER) Agroecologia (Ministério do Desenvolvimento Agrário - MDA), no entorno imediato ou no interior do PNSD.

Tratando-se diretamente da gestão atual do Parque Nacional da Serra do Divisor, Santos (2016) mencionou que trabalham dois colaboradores do ICMBio neste parque, sendo um analista ambiental e um com cargo de Direção e Assessoramento Superior. Mencionou também que não há previsão de receita orçamentária da União exclusiva para tal UC, entretanto, há previsão de destinação de $\mathrm{R} \$ 609.164,80$ ao parque em questão para o biênio 2015-2016, via programa Áreas Protegidas da Amazônia (ARPA).

Considerando que a previsão de destinação citada para dois anos é de $\mathrm{R} \$ 609.164,80$ (isto é, $\mathrm{R} \$ 304.582,40$ para 2015, por exemplo), considerando que a área do parque é de $843.012,28$ hectares e que há dois colaboradores do ICMBio disponíveis para atuação no mesmo, significa dizer que o PNSD tinha a previsão de $\mathrm{R} \$ 0,36$ por hectare em 2015 e um colaborador para 421.506,14 hectares.

\section{Resultados e discussões}

Nas experiências do Amazonas, a gestão compartilhada ou a cogestão de UCs apareceu como excelente alternativa para fazer a captação de recursos financeiros, flexibilizar a contratação de pessoal, aproximar às comunidades deste processo de gestão e fortalecer a participação social via promoção dos conselhos gestores, a partir da execução de cooperações para implantação de ações previstas nos planos de manejo.

A regularização fundiária foi colocada como um dos grandes desafios para aumentar o grau de gestão das UCs no Brasil. No caso do PNSD, o histórico de atuação da SOS Amazônia na região e a sua credibilidade junto às comunidades que vivem dentro e no entorno do parque em questão podem facilitar o processo de aproximação do órgão gestor governamental com as comunidades citadas, de negociação de conflitos e de regularização fundiária propriamente dita.

A localização deste parque nacional é um fator que reforça a necessidade de elevação do nível de gestão do mesmo devido à conclusão recente do asfaltamento da BR-364 até a cidade de Cruzeiro do Sul e por causa da empresa Petrobras ter vencido leilão para prospecção de gás e petróleo em região próxima ao entorno de tal parque, pois o histórico de grandes obras de infraestrutura na Amazônia brasileira é um dos grandes vetores do desmatamento.

Observa-se também a recomendação dos Tribunais de Contas para parcerias de órgãos governamentais com a sociedade civil organizada e com instituições de pesquisa para suprir a carência de pessoal e a grande demanda por investimentos em recursos humanos. Frisa-se ainda que o estado do Acre estabeleceu meta de concretização deste tipo de parceria junto aos tribunais a curto prazo.

O baixo investimento do Brasil na gestão das suas UCs, quando comparado aos investimentos feitos pela Argentina e África do Sul, é agravado pelo fato da maioria delas não terem atividades de geração de receita para sua gestão, como a visitação, exigindo então, a destinação de recursos orçamentários ou propostas de projetos relativos à captação de recursos, as quais poderiam ser elaboradas e executadas por OSCIP, após fechamento de parceria com o órgão gestor competente. Neste sentido, a melhoria do nível de gestão em tais unidades pode gerar receita própria através da visitação e da implantação do plano de manejo ou de uso da área, por exemplo.

Para demonstrar o baixo investimento em pauta e para efetuar comparação com estes dois países, utilizaram-se os dados mencionados por CNUC (2010 apud Medeiros et al., 2011). No Brasil, o orçamento destinado em 2010 correspondia a $\mathrm{R} \$ 4,43$ por hectare destas áreas, enquanto que na Argentina este valor equivalia a R $\$ 21,37$ por hectare e na África do Sul R $\$ 67,09$.

Cabe frisar que o investimento no PNSD, em 2015, foi cerca de 59 vezes menor do que a Argentina investia em 2010, foi aproximadamente 186 vezes menor do que a África do Sul investia neste mesmo ano e foi 12 vezes menor do que o investimento médio brasileiro em 2010.

Já, para comparação relativa ao número de funcionários alocados na gestão de unidades de

(C) Labor \& Engenho, Campinas [SP] Brasil, v.11, n.1, p.05-17, jan./mar. 2017. 
conservação, em 2015, no PNSD, a relação era de um colaborador para 421.506,14 hectares. Com dados de Medeiros et al. (2011), em 2010, na Argentina, tal relação era de um funcionário para cada 2400 hectares, era de um colaborador para 1176 hectares na África do Sul e era de um funcionário para 18600 hectares no Brasil.

Enfatiza-se então que a área sob responsabilidade de um colaborador na Argentina é apenas 0,6\% da área sob responsabilidade de um funcionário no PNSD, na África do Sul é somente 0,3\% da área sob responsabilidade de um colaborador do parque citado e na média das UCs brasileiras equivale aproximadamente a $4 \%$.

\section{Considerações finais}

As experiências de cogestão e gestão compartilhada identificadas, as recomendações do Tribunal de Contas, as experiências da SOS Amazônia e principalmente as informações expostas a respeito dos investimentos em recursos financeiros e humanos no Parque Nacional da Serra do Divisor levantaram argumentos e fundamentaram a defesa pela gestão compartilhada nesta unidade de conservação do Acre.

\section{Referências}

Acre (2001). Lei $N^{o}$ 1.426, de 27 de dezembro de 2001, que dispõe sobre a preservação e conservação das florestas do Estado, institui o Sistema Estadual de Áreas Naturais Protegidas, cria o Conselho Florestal Estadual e o Fundo Estadual de Florestas e dá outras providências. Acre: Diário Oficial.

Acre (2013). Acre em números 2013. Rio Branco [AC]: Secretaria de Estado de Planejamento.

Araújo, E., Barreto, P., Baima, S., \& Gomes, M. (2016). Quais os planos para proteger as unidades de conservação vulneráveis da Amazônia? (36p.). Belém [PA]: Imazon.

Araújo, E., Barreto, P., \& Martins, H. (2015). Áreas protegidas críticas na Amazônia no período de 2012 a 2014. (20 p.). Belém [PA]: Imazon.

Associação SOS Amazônia, Instituto Brasileiro do Meio Ambiente e dos Recursos Naturais Renováveis, \& The Nature Conservancy (1998). Plano de manejo do Parque Nacional da Serra do Divisor, Acre - Brasil. Rio Branco [AC]: SOS Amazônia.

Brasil (1989). Decreto No 97.839, de 16 de junho de 1989, cria o Parque Nacional da Serra do Divisor.

Brasil (2002). Decreto $N^{o} 4.340$, de 22 de agosto de 2002, regulamenta artigos da Lei $\mathrm{n}^{\circ}$ 9.985, de 18 de julho de 2000, que dispõe sobre o Sistema Nacional de unidades de Conservação da Natureza - SNUC, e dá outras providências.

Brasil (2000). Lei $N^{\circ}$ 9.985, de 18 de julho de 2000, que regulamenta o art. 225, § 1ํ, incisos I, II, III e VII, da Constituição Federal, institui o Sistema Nacional de Unidades de Conservação da Natureza.

Brasil (2012). Lei $N^{o} 12.651$, de 25 de maio de 2012, dispõe sobre a proteção da vegetação nativa, altera as Leis nos 6.938, de 31 de agosto de 1981, 9.393, de 19 de dezembro de 1996, e 11.428, de 22 de dezembro de 2006; revoga as Leis nos 4.771, de 15 de setembro de 1965, e 7.754, de 14 de abril de 1989, e a Medida Provisória no 2.166-67, de 24 de agosto de 2001.

Instituto Brasileiro de Geografia e Estatística (2009). Uso da terra e a gestão do território no estado do Acre (Relatório Técnico). Rio de Janeiro [RJ]: IBGE.

Instituto de Conservação e Desenvolvimento Sustentável do Amazonas (2009). Os caminhos da co-gestão nas unidades de conservação no Amazonas. Anais do Congresso Brasileiro de Unidades de Conservação, Curitiba, PR, Brasil, 6. (Mesa Redonda). 
Koury, C. G., \& Guimarães, E. R. (2012). O desafio da gestão participativa, oportunidades, a experiência na RDS Uatumã. Manaus [AM]: Instituto de Conservação e Desenvolvimento Sustentável do Amazonas.

Loureiro, C. F., Azaziel, M., Franca, N., Brasileiro, R. F., Mussi, S. M., Lafaille, T. M. S., \& Leal, W. O. (2008). Educação ambiental e gestão participativa em unidades de conservação. Rio de Janeiro [RJ]: Instituto Brasileiro do Meio Ambiente e dos Recursos Naturais Renováveis.

Malheiros, H., Caldeira, G., \& Mafra, T. (s.d.). Gestão participativa na APA de Guaraqueçaba. Nazaré Paulista [SP]: Instituto de Pesquisas Ecológicas.

Medeiros, R., Young, C. E. F., Pavese, H. B., \& Araújo, F. F. S. (2011). Contribuição das unidades de conservação brasileiras para a economia nacional (Sumário Executivo). Brasília [DF]: UNEP-WCMC.

Oliveira, W. de (2013). Auditoria coordenada em unidades de conservação no bioma Amazônia. Brasília [DF]: Tribunal de Contas da União.

Pádua, M.T.J. (2000). Efetividade das políticas de conservação da biodiversidade. Anais do Congresso Brasileiro de Unidades de Conservação (pp. 104-117), Campo Grande, MS, Brasil, 2.

Santos, S. (2016). Dados para artigo [mensagem pessoal]. Mensagem recebida por <cidalopes.34@gmail.com> em 23 ago. 2016.

WWF Brasil, \& Instituto de Pesquisas Ecológicas (2012). Gestão de unidades de conservação: compartilhando uma experiência de capacitação. Brasília [DF]: WWF Brasil e IPÊ.

WWF Brasil, Secretaria de Estado de Meio Ambiente do Acre, Secretaria de Estado de Floresta do Acre, \& InstiTuto Chico Mendes de Conservação da Biodiversidade (2009). Efetividade de gestão das unidades de conservação no Estado do Acre. Brasília [DF]: WWF Brasil.

Zoneamento Ecológico e Econômico do Acre, \& Instituto Nacional de Pesquisas Espaciais (s. d.). 1 mapa de localização do Parque Nacional da Serra do Divisor elaborado por Tayla da Silva Maia com o uso do ArGis 10.2. Escala: 1:4.500.000. Camada base do ESRI World Imagery. Acesso em: 08 mai. 2015. 